Int. J. Electrochem. Sci., 15 (2020) $6969-6980$

International Journal of

ELECTROCHEMICAL

SCIENCE

www.electrochemsci.org

\title{
Determination of tert-Butylhydroquinone Using a Nanostructured Sensor Based on CdO/SWCNTs and ionic liquid
}

\author{
Akbar Hojjati-Najafabadi ${ }^{1, *}$, Mahbobe S. Rahmanpour ${ }^{2}$, Fatemeh Karimi ${ }^{3, *}$, Hoda Zabihi-Feyzaba ${ }^{3}$, \\ Samira Malekmohammad ${ }^{3, *}$, Shilpi Agarwal ${ }^{4}$,Vinod Kumar Gupta ${ }^{4 *}$, Mohammad A. Khalilzadeh $^{5, *}$ \\ ${ }^{1}$ Faculty of Materials, Metallurgy and Chemistry, School of Materials Science and Engineering, \\ Jiangxi University of Science and Technology, Ganzhou, 341000, PR China \\ ${ }^{2}$ Department of Food Science, Sari Branch, Islamic Azad University, Sari, Iran \\ ${ }^{3}$ Department of Chemical Engineering, Laboratory of Nanotechnology, Quchan University of \\ Technology, Quchan, Iran \\ ${ }^{4}$ Center of Excellence for Advanced materials Research King Abdulaziz University, Jeddah, Saudi \\ Arabia \\ ${ }^{5}$ Department of Biomaterials, College of Natural Resources, North Carolina State University, Raleigh, \\ United States \\ *E-mail: fatemeh.karimi@tdtu.edu.vn (FK), samira_malekmohammadi@yahoo.com (SM) \\ vinodfcy@gmail.com $(\mathrm{VKG})$ and khalilzadeh73@gmail.com (MK)
}

doi: $10.20964 / 2020.07 .85$

Received: 3 April 2020 / Accepted: 25 May 2020 / Published: 10 June 2020

Tert-Butylhydroquinone (TBHQ) is common antioxidant in food and cosmetics industries, yet it has side-effects and can lead to disadvantages to humans. Hence the determination of different concentrations of this material is various samples is of importance and in this light the present work was focused on the voltammetric analysis of the electro-oxidation behavior of TBHQ. Accordingly a composite of $\mathrm{CdO}$ and single wall carbon nanotubes (SWCNTs) was prepared and used to modify an ionic liquid carbon paste electrode (ILCPE) and the resulting electrode was used for the determination of TBHQ. Structure and morphology of the composite was also evaluated through XRD method. Assessments of the electro-oxidation properties of unmodified electrodes and those modifiesed with $\mathrm{CdO} / \mathrm{SWCNTs}$ and 1,3-dipropylimidazolium bromide (CdO/SWCNTs-1,3-DPIBr-ILCPEs) proved the modification to lead to enhanced sensitivity and selectivity. The CdO/SWCNTs-1,3-DPIBr-ILCPEs had a linear response range and detection limit of $0.1-750 \mu \mathrm{mol} \mathrm{L}^{-1}$ and $0.05 \mu \mathrm{mol} \mathrm{L}{ }^{-1}$ and were applied to the determination of tert-Butylhydroquinone in oil samples.

Keywords: 1,3-dipropylimidazolium bromide, $\mathrm{CdO} / \mathrm{SWCNTs}$ nanocomposite, tert-Butylhydroquinone analysis, Antioxidant 


\section{FULL TEXT}

(C) 2020 The Authors. Published by ESG (www.electrochemsci.org). This article is an open access article distributed under the terms and conditions of the Creative Commons Attribution license (http://creativecommons.org/licenses/by/4.0/). 